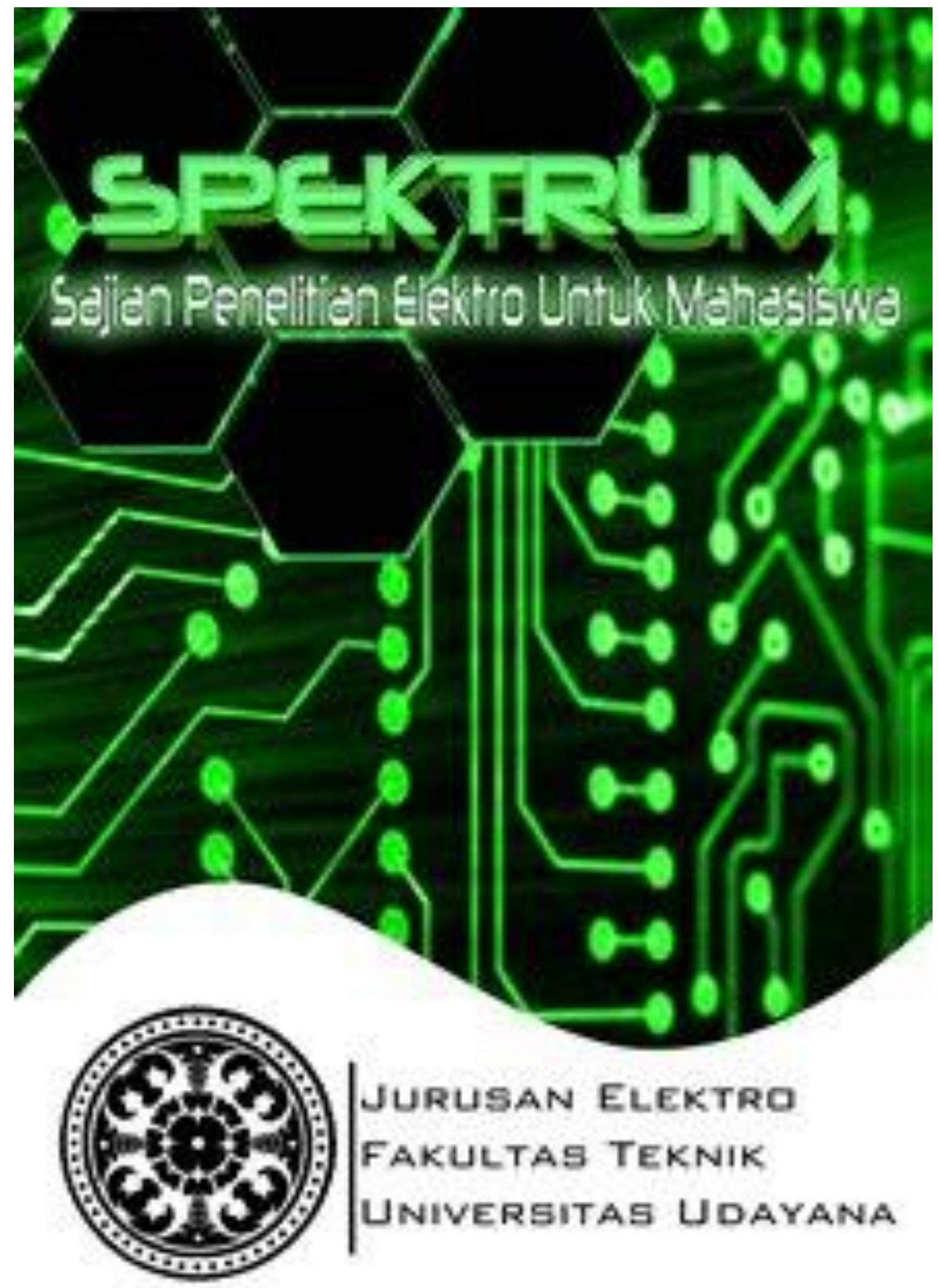




\section{Editorial Team}

\section{Editor-in-Chief}

1. Dr. Ir. Agus Dharma, [SCOPUS ID: 55810411800, h-index: 1] Jurusan Teknik Elektro Fakultas Teknik Universitas Udayana Indonesia

Deputy Editor/Managing Editor

1. Dr. Nyoman Gunantara ST., MT., [Scopus ID: 55672988900, h-index: 2] Jurusan Teknik Elektro Fakultas Teknik Universitas Udayana Indonesia

Editorial Board

1. Dr. IWG Ariastina, [SCOPUS ID: 6507932528, h-index: 1] Jurusan Teknik Elektro Fakultas Teknik Universitas Udayana Indonesia

2. Nyoman Putra Sastra, Universitas Udayana, Indonesia

3. IGAP Raka Agung, Jurusan Teknik Elektro Fakultas Teknik Universitas Udayana Indonesia 


\section{Vol 5, No 1 (2018)}

\section{Jurnal Ilmiah SPEKTRUM}

\section{Table of Contents}

\section{Articles}

PROTOTYPE PENGUKURAN TINGGI DEBIT AIR PADA BENDUNG DENGAN MENGGUNAKAN

$1-4$ SENSOR ULTRASONIK BERBASIS ARDUINO MEGA 2560

Hilmy Jawas, N.M.A.E.D. Wirastuti, Widyadi Setiawan

UJI KEAMANAN KOMUNIKASI VOIP MENGGUNAKAN SISTEM KEAMANAN SRTP-TLS PADA JARINGAN NIRKABEL

Tri Febriana Handayani, Pande Ketut Sudiarta, I Made Oka Widyantara

PERANCANGAN MODUL PEMBELAJARAN HURUF BRAILLE BERBASIS MIKROKONTROLER

UNTUK MEMBANTU PROSES BELAJAR DISABILITAS NETRA

I Putu Agus Padma Diana, I Gusti Agung Putu Raka Agung, Pratolo Rahardjo

PENGUKURAN KINERJA VOIP DENGAN CODEC G.711?, G.711A DAN G.729 DI MEDIA

TRANSMISI NIRKABEL BERBASIS SIP DAN IAX

Putu Sintia Susiani Pande, Pande Ketut Sudiarta, I Made Oka Widyantara

LOAD BALANCING UNTUK PERBANDINGAN KINERJA VIRTUALISASI SERVER VMWARE DAN XEN SERVER

I Gede Primanata, Nyoman Putra Sastra, Dewa Made Wiharta

ANALISIS PEMASANGAN FILTER PASIF DAN AKTIF TERHADAP KANDUNGAN HARMONISA

DAN RUGI-RUGI DAYA GARDU DISTRIBUSI KA 2085 DI PT. PLN (Persero) DISTRIBUSI BALI

RAYON MENGWI

I Putu Budi Aryawan, Antonius Ibi Weking, I Wayan Rinas

STUDI KOORDINASI KERJA RELE DIFERENSIAL DAN RELE RESTRICTED EARTH FAULT

SETELAH UPRATING PADA TRANSFORMATOR II DI GI KAPAL

I Made Dwi Cahyadi Jaya, I Gede Dyana Arjana, A.A Gede Maharta Pemayun

ANALISIS KEANDALAN PADA PENYULANG ARJUNA DENGAN TERPASANGNYA RECLOSER

DOUBLE SIX MENGGUNAKAN METODE SECTION TECHNIQUE

I Ketut Adi Wicaksana, I Wayan Rinas, I Wayan Arta Wijaya

ANALISIS KETIDAKSEIMBANGAN BEBAN PADA GARDU DISTRIBUSI KA 2085 DI PT. PLN

$62-67$

(Persero) DISTRIBUSI BALI RAYON MENGWI BADUNG

R. Suputra, A. I. Weking, W. Rinas

ANALISIS UNJUK KERJA ZERO FORCING EQUALIZER PADA SISTEM OFDM MIMO

68-73

R. A. Prayitno, N.M.A.E.D. Wirastuti, I.G.A.K.D.D. Hartawan

SISTEM PAKAR DETEKSI KERUSAKAN HARDWARE HANDPHONE BERBASIS DESKTOP

74-81

Eka Lilla Ananta, Lie Jasa, Putu Arya Mertasana 
PEMERATAAN BEBAN PADA GARDU KD 056 PENYULANG TABANAN PT PLN (PERSERO)

DISTRIBUSI BALI AREA BALI SELATAN

I Putu Agus Semara Putra, I Ketut Wijaya, I Made Mataram

AUGMENTED REALITY BERBASIS ANDROID UNTUK PENGENALAN PERALATAN

89-94

LABORATORIUM

I Kadek Arya Wiratama, Duman Care Khrisne, Made Sudarma

STUDI POLA OPERASI DAN KONSUMSI ENERGI POMPA KOLAM RENANG DI HOTEL RAMADA

$95-100$

CAMAKILA DAN RAMADA BINTANG

I Gede Ginarsa, I N. Satya kumara, A. Ibi Weking

OPTIMASI NIRKABEL LOCAL AREA NETWORK FAKULTAS TEKNIK KAMPUS SUDIRMAN

101-108

UNIVERSITAS UDAYANA

Komang Yuda Krisnawan, Nyoman Putra Sastra, N.M.A.E.D. Wirastuti

ANALISA PEMASANGAN FILTER HYBRID TERHADAP BEBAN-BEBAN NON-LINIER PADA

BLUE POINT BAY VILLA DAN SPA

I Wayan Dedy Setiawan, I Wayan Rinas, Antonius Ibi Weking

ANALISIS HASIL DRIVE TEST MENGGUNAKAN SOFTWARE GENEX PROBE DAN GENEX

ASSISTANT PADA JARINGAN LTE

S.G.Y.P. Putra, P.K. Sudiarta, G. Sukadarmika

STUDI ANALISIS KEMAMPUAN PENYEDIAAN SUPLAI DAYA AKIBAT PENINGKATAN BEBAN

$123-129$

DI GARDU INDUK NUSA DUA

Nur Ayu Puspita Indra Pratiwi, I Gede Dyana Arjana, Antonius Ibi Weking

RANCANG BANGUN MONITORING ENERGI LISTRIK MENGGUNAKAN SMS BERBASIS

MIKROKONTROLER ATMEGA328

$130-138$

Raden Ajeng Gusti Ramadhianti, Ir. Cok Gede Indra Partha, I Gusti Agung Pt Raka Agung

RANCANG BANGUN MONITORING DAN PENYIMPANAN NILAI DAYA LISTRIK SECARA REAL TIME PADA BASIS DATA

I Dewa Gde Bayu Wiranatha, Cok Gede Indra Partha, Widyadi Setiawan

Studi Pengaruh Jenis Refrigerant Terhadap Pemakaian Daya Listrik Pada Mesin

Pengkondisian Udara (AC)

I Nyoman Mudana, Yanu Prapto Sudarmojo, I Gusti Ngurah Janardana

Studi Analisis Pengaruh Perubahan Posisi Terhadap Efisiensi Panel Surya LPJU By Pass

$151-156$

Ngurah Rai

I Ketut Suantika, Wayan Rinas, I Made Suartika

Rancang Bangun Kapasitor Bank Otomatis Berbasis Mikrokontroler ATmega 328P Untuk

$157-163$

Perbaikan Faktor Daya

Putu Angga Juliantara, I Wayan Arta Wijaya, Cok Gede Indra Partha

Prototipe Mobile Station Untuk Perekaman Kandungan Udara

$164-170$

Gusti Ketut Bella, Nyoman Putra Sastra, I G. A. K. Diafari Djuni Hartawan 


\title{
OPTIMASI NIRKABEL LOCAL AREA NETWORK FAKULTAS TEKNIK KAMPUS SUDIRMAN UNIVERSITAS UDAYANA
}

\author{
Komang Yuda Krisnawan ${ }^{1}$, Nyoman Putra Sastra ${ }^{2}$, N.M.A.E.D. Wirastuti ${ }^{3}$ \\ Jurusan Teknik Elektro, Fakultas Teknik, Universitas Udayana Email: \\ putra.sastra@unud.ac.id ${ }^{2}$
}

\begin{abstract}
ABSTRAK
Salah satu perubahan di bidang telekomunikasi yaitu penggunaan teknologi nirkabel. Teknologi nirkabel diterapkan pada jaringan komputer yang lebih dikenal dengan Wireless Local Area Network (WLAN). Pengukuran kualitas cakupan jaringan dapat dilihat dari kategori kelambatan atau penangguhan, kelebihan antrian pada jaringan, peningkatan trafik, dan hasil keluaran. Dengan menggunakan software Wi-Fi Analyzer dan Ekahau didapatkan nilai Quality of Service (QoS) untuk melihat seberapa baik cakupan jaringan nirkabel yang sudah ada. Hasil pengukuran dianalisis untuk mendapat penyesuaian rumusan cakupan area nirkabel sehingga dapat menemukan jangkauan maksimum yang digunakan sebagai acuan dalam menempatkan access point yang ideal. Penambahan titik access point dilakukan pada seluruh gedung dimana pada titik sebelumnya beberapa area tidak dapat dijangkau secara keseluruhan.
\end{abstract}

Kata kunci : Coverage area Wireless, MAPL, Optimasi, Wireless

\section{ABSTRACT}

One of the changes in the field of telecommunications is the use of wireless technology. Wireless technology is applied to computer networks better known as Wireless Local Area Network (WLAN). Network coverage quality measurements can be seen from categories of delay or suspension, excess queues on the network, increased traffic, and output results. By using Wi-Fi Analyzer and Ekahau software we get the Quality of Service (QoS) value to see how good the coverage of the existing wireless network is. The result of the measurement is analyzed to get the adjustment of the wireless area coverage formula so that it can find the maximum range used as a reference in placing the ideal access point. The addition of access point points is done on all buildings where at some point the area can not be reached as a whole.

Keywords: Coverage area Wireless, MAPL, Optimization, Wireless

\section{PENDAHULUAN}

Teknologi Wireless Fidelity (Wi-Fi) merupakan suatu teknologi yang menggunakan udara (gelombang radio) sebagai media transmisinya sehingga jika ditempatkan di suatu bangunan, perangkat $\mathrm{Wi}$ Fi mampu menjangkau seluruh sisi bangunan dengan kondisi-kondisi tertentu pada suatu gedung. Teknologi Wi-Fi, dengan standar IEEE $802.11 \mathrm{a} / \mathrm{b} / \mathrm{g}$ yang bekerja pada frekuensi 2.4GHz, saat ini banyak dijumpai di hampir semua tempat [1].

Namun suatu jaringan Wi-Fi dibangun tidak mudah karena memerlukan suatu perhitungan yang matang agar kinerjanya memuaskan dan dapat benar-benar menghemat biaya. Contohnya yaitu pada suatu gedung, dapat diketahui dari penerimaan sinyal yang diterima oleh pengguna,melaluiAcess Point. Tentunya penerimaan sinyal yang naik turun atau yang lemah tidak dikehendaki. Apabila penempatan Acess Point di dalam suatu gedung dapat dilakukan secara tepat maka kinerja jaringan Wi-Fi akan lebih optimal.

Penelitian yang membahas coverage area Wireless sudah cukup banyak dilakukan.Beberapa diantaranya yaitu "Optimasi Sistem Wi-Fi di PENS-ITS dengan Menggunakan Algoritma Genetika". Penelitian tersebut menjelaskan bahwa coverage area dari access point dapat ditentukan melalui perhitungan, tanpa melakukan survey lapangan yang aktual. Hal ini akan sangat membantu dalam mengoptimalkan jaringan Wi-Fi dan mengurangi biaya implementasi. Algoritma genetika digunakan sebagai metode pemodelan dengan sistem Wi-Fi. Dari hasil pengukuran diperoleh nilai level daya terima 
yang digunakan untuk menentukan jarak antara pemancar ke penerima. Jarak inilah nantinya akan menjadi masukan dalam permodelan dengan metode Algoritma Genetika [2]. Penelitian selanjutnya yaitu "Perancangan Penempatan Access Point untuk Jaringan Wifi Pada Kereta Api Penumpang". Pada penelitian ini badan kereta api berbahan dasar besi dan baja. Beberapa aspek yang perlu diperhatikan seperti propagasi dan coverage area untuk menghasilkan perancangan yang efektif [3].

Dalam penelitian ini akan diukur kualitas cakupan jaringan yang dilihat dari kategori kelambatan atau penangguhan, kelebihan antrian pada jaringan, peningkatan trafik, dan hasil keluaran. Pengukuran penerimaan sinyal akan dilakukan langsung di beberapa titik di dalam gedung kampus dengan sebuah alat bantu pengukur penerimaan kuat sinyal Wi-Fi. Tidak semua area di gedung Fakultas Teknik Kampus Sudirman akan diukur dan dianalisis tetapi dipilih area yang paling sering digunakan sebagai pusat kegiatan mahasiswa untuk mengakses jaringan internet, SSID yang akan diukur ada satu buah, yaitu SSID imissu@berbudaya.

Hasil akhir dari penelitian ini adalah sebuah rekomendasi tentang penempatan Acess Point yang paling efektif kepada penyedia layanan Wi-Fi agar dapat mengoptimalkan jaringan Wireless LAN-nya.

\section{KAJIAN PUSTAKA}

\subsection{Wireless Fidelity (Wi-Fi)}

Wi-Fi mengacu pada jenis IEEE 802.11 Wireless Local Area Network (WLAN). WLAN memperluas jangkauan Local Area Networks (LAN) dengan menyediakan konektivitas nirkabel. Dirancang awalnya untuk penggantian kabel di lingkungan perusahaan, WLAN telah menjadi sangat populer dalam menyediakan konektivitas IP di lingkungan perumahan, kantor kecil dan kampus. WLAN telah mengalami pertumbuhan fenomenal dan sekarang merupakan bagian penting dari jaringan komputer. Ada dua standar WLAN yang dominan; IEEE 802.11 dan HiperLAN [1].

Gambar 1merupakan arsitektur 802.11 LAN seperti arsitekturseluler, sistem ini dibagibagi menjadi beberapa sel. Tiap sel yangdisebut dengan Basic Service Set atau BSS dikontrol oleh Base Stationyang disebut dengan Access Point atau biasa disingkat AP. Ada 2 jenis BSS, yaitu:
1. Independent BSS (IBSS), yaitu sistem BSS apabila Wireless Station(WS) tidak dihubungkan menggunakan AP.

2. Infrastructure BSS, yaitu sistem BSS apabila terdapat AP yang menghubungkan Wireless Station (WS).

Untuk arsitektur dasar jaringan Wi-Fi dapat dilihat pada Gambar 1 .

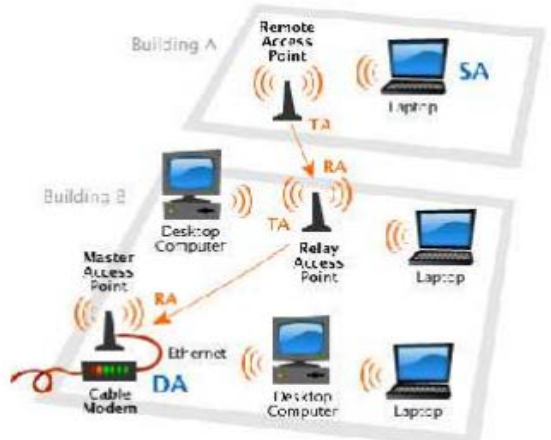

\section{Gambar 1 Arsitektur Dasar Jaringan Wi-Fi}

\subsection{OSI Layer}

Model Open Systems Interconnection (OSI) adalah alat referensi untuk memahami komunikasi data antara dua sistem jaringan. Ini membagi proses komunikasi menjadi tujuh lapisan. Setiap lapisan melakukan fungsi spesifik untuk mendukung lapisan di atasnya dan menawarkan layanan ke lapisan di bawahnya. Tiga lapisan terendah fokus pada lalu lintas yang lewat melalui jaringan ke sistem akhir. Empat lapisan teratas ikut berperan dalam sistem akhir untuk menyelesaikan prosesnya. Manfaat utama dari model OSI adalah membantu pengguna memahami gambaran besar jaringan, membantu pengguna memahami bagaimana elemen perangkat keras dan perangkat lunak berfungsi bersama dan membuat pemecahan masalah lebih mudah dengan memisahkan jaringan menjadi bagian yang mudah dikelola. Terdapat 7 layer pada model OSI. Setiap layer bertanggungjawab secara khusus pada proses komunikasi data [4].

Gambar 2 merupakan model dari OSI Layer yang masing-masing mempunyai fungsi sebagai berikut:

1. The Phisical Layer: mendefinisikan spesifikasi konektor dan antarmuka, serta persyaratan media (kabel). Spesifikasi listrik, mekanik, fungsional, dan prosedural disediakan untuk mengirim aliran bit pada jaringan komputer. 
2. The Data Link Layer: Memungkinkan perangkat mengakses jaringan untuk mengirim dan menerima pesan.

3. The Network Layer: menyediakan sistem pengalamatan logis end-to-end sehingga satu paket data dapat disalurkan ke beberapa jaringan lapisan 2 (Ethernet, Token Ring, Frame Relay, dll.).

4. The Transport Layer: menawarkan komunikasi end-to-end antara perangkat akhir melalui jaringan. Bergantung pada aplikasinya, lapisan transport menawarkan komunikasi yang andal, berorientasi koneksi, tanpa sambungan, dan besteffort.

5. The Session Layer: menyediakan berbagai layanan, termasuk melacak jumlah byte yang setiap akhir sesi telah diketahui menerima dari ujung sesi lainnya. Lapisan sesi ini memungkinkan aplikasi berfungsi pada perangkat untuk membuat, mengelola, dan menghentikan dialog melalui jaringan.

6. The Presentation Layer: bertanggung jawab atas bagaimana aplikasi memformat data yang akan dikirim ke jaringan. Lapisan presentasi pada dasarnya memungkinkan aplikasi membaca (atau mengerti) pesannya.

7. The Aplication Layer: menyediakan antarmuka bagi pengguna akhir yang mengoperasikan perangkat yang terhubung ke jaringan. Lapisan ini adalah apa yang pengguna lihat, dalam hal memuat aplikasi (seperti browser Web atau e-mail); Artinya, lapisan aplikasi ini adalah data yang dilihat pengguna saat menggunakan aplikasi ini.

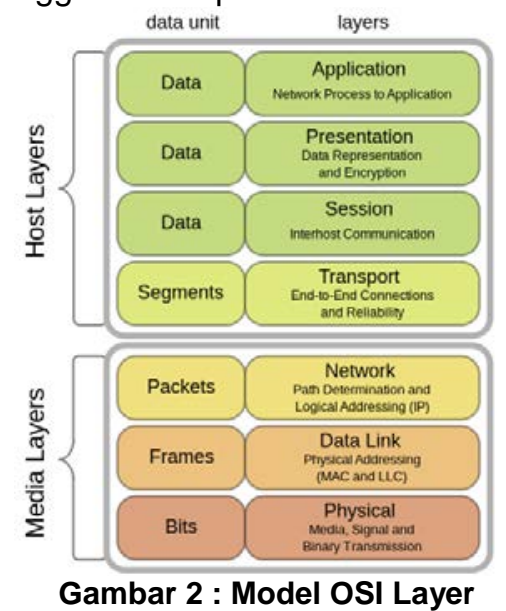

Standar 802.11 yang paling banyak digunakan memiliki banyak ekstensi dan masih banyak lagi yang sedang dikembangkan. Pertama kali diperkenalkan pada tahun 1999, standar IEEE 802.11 terutama dikembangkan dengan mengingat lingkungan rumah dan kantor untuk konektivitas area lokal nirkabel. Standar awal memberikan data rate maksimum 2 Mbps per AP yang meningkat menjadi $11 \mathrm{Mbps}$ per AP. IEEE 802.11g dan IEEE 802.11a memberikan kecepatan data maksimum 54Mbps per AP dengan menggunakan berbagai metode untuk tingkatkan kecepatan data maksimum. Perangkat WLAN berbasis IEEE $802.11 \mathrm{~g}$ saat ini menawarkan data rate $100-125 \mathrm{Mbps}$ [5].

\subsection{Wireless Ubiquity Unifi}

The UniFi Wi-Fi System adalah solusi jalur akses terukur yang dirancang untuk mudah digunakan dan dikelola. Model dalam ruangan UniFi Access Point (AP) memiliki desain yang ramping dan dapat dipasang dengan mudah ke genteng atau dinding langit-langit menggunakan perangkat keras pemasangan yang disertakan. Model outdoor UniFi AP (UAP) memiliki faktor bentuk yang dibangun untuk bertahan di luar ruangan [6].

\subsection{Wi-FiAnalyzer}

Wi-FiAnalyzer dapat membantu Anda mengidentifikasi masalah Wi-Fi, menemukan saluran terbaik atau tempat terbaik untuk router / access point dengan memutar PC / laptop, tablet, atau perangkat seluler ke dalam penganalisis untuk jaringan nirkabel [7].

\section{METODE PENELITIAN}

Dalam penelitian Optimasi Wireless LAN ini penulis mengambil lokasi di Fakultas Teknik Kampus Sudirman Universitas Udayana ini Dalam penelitian ini, jenis data yang digunakan yaitu data sekunder yang diperoleh secara langsung dari Fakultas Teknik Kampus Sudirman Universitas Udayana dengan melakukan wawancara terhadap mahasiswa yang menggunakan Wi-Fi. Data tersebut berupa kondisi dan status Wi-Fi yang ada saat ini.

\subsection{Tahapan Penelitian}

Dalam penulisan penelitian ini, terdapat beberapa tahapan yang dilakukan yang dapat dilihat pada Gambar 3.

\subsection{Standar IEEE 802.11}




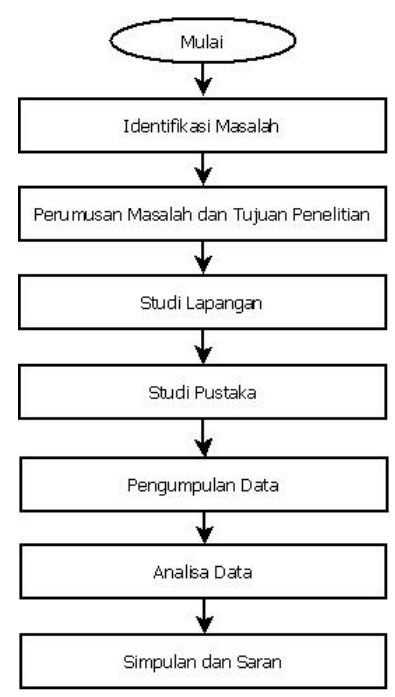

Gambar 3 Flowchart Tahapan Penelitian

\section{Identifikasi Masalah}

Pada tahap ini kegiatan yang dilakukan adalah: mengetahui kualitas sinyal Acess Point pada area gedung Fakultas Teknik Kampus Sudirman Universitas Udayana khususnya pada gedung $C$ dan gedung Dyang akan digunakan dapat dilihat melaluiTabel 1 berikut. Tabel 1 Pengaruh Penempatan Acess Point pada Gedung C dan D

\begin{tabular}{|l|l|l|l|}
\hline $\begin{array}{c}\text { Nama } \\
\text { Ruangan }\end{array}$ & $\begin{array}{l}\text { Sinyal } \\
\mathrm{dBm}\end{array}$ & $\begin{array}{l}\text { Kualitas } \\
\text { Sinyal }\end{array}$ & $\begin{array}{c}\text { Letak Access } \\
\text { Point }\end{array}$ \\
\hline $\begin{array}{l}\text { Koridor } \\
\text { JurusanT } \\
\text { eknik } \\
\text { Elektro }\end{array}$ & $\begin{array}{l}-41 \\
\mathrm{dBm}\end{array}$ & Baik & $\begin{array}{l}\text { Koridor Jurusan } \\
\text { Teknik Elektro }\end{array}$ \\
\hline D1.1 & $\begin{array}{l}-60 \\
\mathrm{dBm}\end{array}$ & Cukup & $\begin{array}{l}\text { Koridor Jurusan } \\
\text { Teknik Elektro }\end{array}$ \\
\hline D1.2 & $\begin{array}{l}-70 \\
\mathrm{dBm}\end{array}$ & Kurang & $\begin{array}{l}\text { Koridor Jurusan } \\
\text { Teknik Elektro }\end{array}$ \\
\hline D1.3 & $\begin{array}{l}-73 \\
\mathrm{dBm}\end{array}$ & Kurang & $\begin{array}{l}\text { Koridor Jurusan } \\
\text { Teknik Elektro }\end{array}$ \\
\hline D1.4 & $\begin{array}{l}-75 \\
\mathrm{dBm}\end{array}$ & Kurang & $\begin{array}{l}\text { Koridor Jurusan } \\
\text { Teknik Elektro }\end{array}$ \\
\hline D2.1 & $\begin{array}{l}-85 \\
\mathrm{dBm}\end{array}$ & Buruk & $\begin{array}{l}\text { Koridor Jurusan } \\
\text { Teknik Elektro }\end{array}$ \\
\hline D2.2 & $\begin{array}{l}-90 \\
\mathrm{dBm}\end{array}$ & Buruk & $\begin{array}{l}\text { Koridor Jurusan } \\
\text { Teknik Elektro }\end{array}$ \\
\hline $\begin{array}{l}\text { Koridor } \\
\text { Ruang } \\
\text { C3.3 }\end{array}$ & $\begin{array}{l}-41 \\
\mathrm{dBm}\end{array}$ & Baik & $\begin{array}{l}\text { Koridor Ruang } \\
\text { C3.3 }\end{array}$ \\
\hline D3.1 & $\begin{array}{l}-82 \\
\mathrm{dBm}\end{array}$ & Buruk & $\begin{array}{l}\text { Koridor Ruang } \\
\text { C3.3 }\end{array}$ \\
\hline D3.2 & $\begin{array}{l}-85 \\
\mathrm{dBm}\end{array}$ & Buruk & $\begin{array}{l}\text { Koridor Ruang } \\
\text { C3.3 }\end{array}$ \\
\hline
\end{tabular}

Tabel 1memaparkan nama ruangan yang akan diukur menggunakan Wi-Fi Analyzer, channel yang digunakan, sinyal $\mathrm{dBm}$ yang menjadi tolak ukur pada sinyal yang didapatkan, kualitas sinyal yang menjadi acuan apakah sinyal itu dapat dikatakan bagus atau tidak, dan penempatan pada prangkat Acess Point (CISCO system,inc).

\section{Perumusan Masalah dan Tujuan Penelitian}

Berdasarkan identifikasi masalah yang telah dilakukan, dapat dirumuskan beberapa masalah yaitu :

a. Bagaimana kualitas sinyal Acess Point pada area gedung Fakultas Teknik Kampus Sudirman Universitas Udayana khususnya pada gedung $C$ dan $D$ ?

b. Bagaimana pengaruh struktur gedung dan luas area Fakultas Teknik Kampus Sudirman Universitas Udayana terhadap kualitas sinyal yang didapatkan?

c. Bagaimana mengoptimasi penempatan access point pada area gedung Fakultas Teknik Kampus Sudirman Universitas Udayana?

Dari masalah yang ada, tujuan yang ingin dicapai pada penelitian ini yaitu :

a. Mengetahui kualitas sinyal Acess Point pada area gedung Fakultas Teknik Kampus Sudirman Universitas Udayana khususnya pada gedung $C$ dan $D$.

b. Mengatur pengaruh struktur gedung dan luas area Fakultas Teknik Kampus Sudirman Universitas Udayanaterhadap kualitas sinyal yang didapatkan.

c. Mengetahui optimasi penempatan access point pada area gedung Fakultas Teknik Kampus Sudirman Universitas Udayana.

3. Studi Lapangan

Studi lapangan dimaksudkan agar peneliti memperoleh gambaran umum tentang sistem yang akan dibuat dan memahami permasalah yang telah dirumuskan sebelumnya, bagaimana implementasi/penerapannya di Fakultas Teknik Kampus Sudirman Universitas Udayana.

\section{Studi Pustaka}

Studi literatur ini dilakukan untuk memahami teori-teori yang berhubungan dengan pemecahan masalah. Selain itu juga untuk mengetahui penelitian-penelitian terdahulu yang telah dilakukan untuk menyakinkan bahwa yang diteliti saat ini belum pernah dilakukan atau merupakan pengembangan dari penelitian terdahulu. Konsep yang harus dipahami oleh peneliti antara lain mengenai perancangan sistem informasi konsep Optimasi Jaringan Wireless LAN di Falkutas Teknik Elektro Sudirman Udayana.

\section{Pengumpulan Data}


Tahap pengumpulan data ini dilakukan untuk memperoleh bahan penelitian sesuai dengan tujuan peneliti yang telah ditetapkan. Data-data yang dibutuhkan dalam penelitian ini diperoleh dari data katalog-katalog Optimasi Jaringan Wireless LAN di Falkutas Teknik Elektro Sudirman Udayana dari pengamatan maupun dari hasil wawancara. Pengambilan data dilakukan di Fakultas Teknik Elektro Sudirman dengan batasan-batasan yang telah ditetapkan, meliputi data-data pada Optimasi Jaringan Wireless LAN di Falkutas Teknik Elektro Sudirman Udayana.

\section{Analisis Data}

Tahap Analisa data ini dilakukan untuk menganalisa dan mengolah data yang telah di kumpulkan sehingga dapat menghasilkan simpulan dan saran. Dalam penentuan penambahan Acess Point diperlukan pengukuran cakupan area dari jarak pancar pada setiap Acess Point. Selain itu juga jumlah user yang akan mengakses SSID "ImissU@berbudaya" harus dikaji terlebih dahulu apakah area tersebut sangat diperlukan dalam penambahn perangkat Acess Point atau tidak berbanding dengan banyaknya user yang akan mengakses dilokasi yang akan ditambahkan.

\section{HASIL DAN PEMBAHASAN}

\subsection{Hasil}

\section{Analisis Coverage area Menggunakan MAPL}

Analisis coverage area WLAN $802.11 \mathrm{~b} / \mathrm{g}$ menggunakan data standar IEEE802.11 b/g dan data asumsi yang diperoleh dari berbagai literature yangberhubungan dengan standar IEEE 802.11 dan Wireless Local Area Network (WLAN). Pada penelitian ini, pemancar yang digunakan adalah Unifi Ubiquity dengan antenna omnidirectional. Menggunakan perhitungan Maximum Allowed Path Loss (MAPL) agar dapat mengetahui luas coverage AP. Untuk menghitung MAPL digunakan persamaan [1] dan [2] :

$M A P L=E I R P-$ Margin $-S_{R X}$

$E I R P=P_{\text {Transmit }}-L_{\text {Saluran }}+G_{\text {antena }} \ldots \ldots \ldots \ldots . .$. [2] Dengan:

EIRP (Effective Isotropics Radiated Power) : Total energy yang dikeluarkan sebuah AP

$P_{\text {Transmit }}:$ PowerTransmiter

$G_{\text {Antena }}:$ GainAntena

Fading Margin: 10 dB typical WLAN $S_{R X} \quad$ : Sensitivitas Penerima

Margin = Fading Margin $=10 \mathrm{~dB}$

(typical untuk WLAN)

$S_{R X}=$ Sensitivitas Penerima $=$ MCS15
@ -70dBm frekuensi 802.11n

(spesifikasi pada alat)

$$
\begin{aligned}
& M A P L=P_{\text {Transmit }}-L_{\text {Saluran }}+G_{\text {Antena }}-\text { Margin }- \\
& S_{R X} \\
& \text { MAPL }=30-0+4-10-(-70) \\
& M A P L=94 d B \\
& M A P L=L \text {, } \\
& \text { maka lanjut ke persamaan: } \\
& L \quad=L F S+(2 \times 10)+(3 \times 5) \\
& L \quad=L_{F S}+35 \\
& L_{F S} \quad=M A P L-35 \\
& L_{F S} \quad=94-35 \\
& \left(\frac{4 \pi d}{\lambda}\right) L_{F S} \quad=59 D b \\
& \text { LFS } \quad=20 \log 61 \\
& \begin{aligned}
d & =20 \log \left(\frac{4 \pi d}{\lambda}\right) \\
d & =11,166 \mathrm{~m}
\end{aligned}
\end{aligned}
$$

Jadi, panjang diameter AP adalah 11,166 m.

\section{Pengukuran Sinyal}

Pengukuran Sinyal dilakukan pada Acess Pointyang teletak di Gedung Fakultas Teknik Kampus Sudirman Universitas Udayana pada Gedung C dan Gedung D. Sinyal pada jaringan Acess Pointbaru menjangkau hampir semua daerah Gedung kecuali gedung D yang berlum tepasang titik Acess Point sehingga untuk uji coba harus menggunakan penemptan Acess

\section{a. Point di penempatan Gedung $\mathbf{C}$}

Tabel 4, pengujian sinyal dilakukan dengan cara mengukur jangkauan dari titik terjauh dari Access Point dalam hal ini pengukuran sinyal Wirelessdilakukan pada titik-titik terjauh dari area Gedung Fakultas Teknik Kampus Sudirman Universitas Udayana.

Tabel 4 Pengaruh Penempatan Acess Point Gedung C Lantai 1, 2 dan 3

\begin{tabular}{|c|c|c|c|}
\hline Ruangan & $\begin{array}{c}\text { Sinyal } \\
\mathrm{dBm}\end{array}$ & $\begin{array}{c}\text { Kualitas } \\
\text { Sinyal }\end{array}$ & $\begin{array}{c}\text { Penempatan Acess } \\
\text { Point\& Mac } \\
\text { Address }\end{array}$ \\
\hline $\begin{array}{c}\text { Koridor } \\
\text { Jurusan } \\
\text { Arsitek }\end{array}$ & $\begin{array}{c}-75 \\
\mathrm{dBm}\end{array}$ & Kurang & $\begin{array}{c}\text { Koridor Teknik } \\
\text { Jurusan Elektro \& } \\
\text { Mac } \\
\text { (2c:3e:cf:f1:d8:90) }\end{array}$ \\
\hline $\begin{array}{c}\text { Koridor } \\
\text { Jurusan } \\
\text { Sipil }\end{array}$ & $\begin{array}{c}-65 \\
\mathrm{dBm}\end{array}$ & Cukup & $\begin{array}{c}\text { Koridor Teknik } \\
\text { Jurusan Elektro \& } \\
\text { Mac } \\
\text { (2c:3e:cf:f1:d8:90) }\end{array}$ \\
\hline $\begin{array}{c}\text { Koridor } \\
\text { Jurusan } \\
\text { Elektro }\end{array}$ & $\begin{array}{c}-41 \\
\mathrm{dBm}\end{array}$ & Baik & $\begin{array}{c}\text { Koridor Teknik } \\
\text { Jurusan Elektro \& } \\
\text { Mac } \\
\text { (2c:3e:cf:f1:d8:90) }\end{array}$ \\
\hline $\begin{array}{c}\text { Koridor } \\
\text { Jurusan } \\
\text { Mesin }\end{array}$ & $\begin{array}{c}-70 \\
\mathrm{dBm}\end{array}$ & Kurang & $\begin{array}{c}\text { Koridor Teknik } \\
\text { Jurusan Elektro \& } \\
\text { Mac } \\
\text { (2c:3e:cf:f1:d8:90) }\end{array}$ \\
\hline C.2.1 & -90 & Buruk & $\begin{array}{c}\text { Koridor Teknik } \\
\text { Jurusan Elektro \& }\end{array}$ \\
\hline
\end{tabular}




\begin{tabular}{|c|c|c|c|}
\hline & & & $\begin{array}{c}\text { Mac } \\
\text { (2c:3e:cf:f1:d8:90) }\end{array}$ \\
\hline 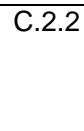 & $\begin{array}{c}-85 \\
\mathrm{dBm}\end{array}$ & Buruk & $\begin{array}{c}\text { Koridor Teknik } \\
\text { Jurusan Elektro \& } \\
\text { Mac } \\
\text { (2c:3e:cf:f1:d8:90) }\end{array}$ \\
\hline C.2.3 & $\begin{array}{c}-70 \\
\mathrm{dBm}\end{array}$ & Kurang & $\begin{array}{c}\text { Koridor Teknik } \\
\text { Jurusan Elektro \& } \\
\text { Mac } \\
\text { (2c:3e:cf:f1:d8:90) }\end{array}$ \\
\hline C.2.4 & $\begin{array}{c}-74 \\
\mathrm{dBm}\end{array}$ & Kurang & $\begin{array}{c}\text { Koridor Teknik } \\
\text { Jurusan Elektro \& } \\
\text { Mac } \\
\text { (2c:3e:cf:f1:d8:90) }\end{array}$ \\
\hline C.3.1 & $\begin{array}{c}-73 \\
\mathrm{dBm}\end{array}$ & Kurang & $\begin{array}{c}\text { Koridor Ruang } \\
\text { C.3.3 \& Mac } \\
\text { (34:a8:4e:f9:70:80) }\end{array}$ \\
\hline C.3.2 & $\begin{array}{c}-65 \\
\mathrm{dBm}\end{array}$ & Cukup & $\begin{array}{c}\text { Koridor Ruang } \\
\text { C.3.3 \& Mac } \\
\text { (34:a8:4e:f9:70:80) }\end{array}$ \\
\hline C.3.3 & $\begin{array}{c}-56 \\
\mathrm{dBm}\end{array}$ & Cukup & $\begin{array}{c}\text { Koridor Ruang } \\
\text { C.3.3 \& Mac } \\
\text { (34:a8:4e:f9:70:80) }\end{array}$ \\
\hline C.3.4 & $\begin{array}{l}-70 \\
\mathrm{dBm}\end{array}$ & Sedang & $\begin{array}{c}\text { Koridor Ruang } \\
\text { C.3.3 \& Mac } \\
\text { (34:a8:4e:f9:70:80) }\end{array}$ \\
\hline
\end{tabular}

\section{b. Point Penempatan di Gedung D}

Pengujian pengukuran sinyal di area Gedung D dapat dilihat di Tabel 5.

Tabel 5 Pengaruh Penempatan Acess Point Gedung D Lantai 1, 2 dan 3

\begin{tabular}{|c|c|c|c|}
\hline Ruangan & $\begin{array}{l}\text { Sinyal } \\
\mathrm{dBm}\end{array}$ & $\begin{array}{c}\text { Kualitas } \\
\text { Sinyal }\end{array}$ & $\begin{array}{c}\text { Penempatan Acess } \\
\text { Point\& Mac } \\
\text { Address } \\
\end{array}$ \\
\hline D.1.1 & $\begin{array}{l}-60 \\
d B m\end{array}$ & Cukup & $\begin{array}{c}\text { Koridor Teknik } \\
\text { Jurusan Elektro \& } \\
\text { Mac } \\
\text { (2c:3e:cf:f1:d8:90) }\end{array}$ \\
\hline D.1.2 & $\begin{array}{c}-70 \\
d B m\end{array}$ & Kurang & $\begin{array}{c}\text { Koridor Teknik } \\
\text { Jurusan Elektro \& } \\
\text { Mac } \\
\text { (2c:3e:cf:f1:d8:90) }\end{array}$ \\
\hline D.1.3 & $\begin{array}{c}-73 \\
d B m\end{array}$ & Kurang & $\begin{array}{c}\text { Koridor Teknik } \\
\text { Jurusan Elektro \& } \\
\text { Mac } \\
\text { (2c:3e:cf:f1:d8:90) }\end{array}$ \\
\hline D.1.4 & $\begin{array}{c}-75 \\
d B m\end{array}$ & Kurang & $\begin{array}{c}\text { Koridor Teknik } \\
\text { Jurusan Elektro \& } \\
\text { Mac } \\
\text { (2c:3e:cf:f1:d8:90) }\end{array}$ \\
\hline D.2.1 & $\begin{array}{c}-85 \\
d B m\end{array}$ & Buruk & $\begin{array}{c}\text { Koridor Teknik } \\
\text { Jurusan Elektro \& } \\
\text { Mac } \\
\text { (2c:3e:cf:f1:d8:90) }\end{array}$ \\
\hline D.2.2 & $\begin{array}{l}-90 \\
\mathrm{dBm}\end{array}$ & Buruk & $\begin{array}{c}\text { Koridor Teknik } \\
\text { Jurusan Elektro \& } \\
\text { Mac } \\
\text { (2c:3e:cf:f1:d8:90) }\end{array}$ \\
\hline D.3.1 & $\begin{array}{c}-82 \\
\mathrm{dBm}\end{array}$ & Kurang & $\begin{array}{c}\text { Koridor Ruang } \\
\text { C.3.3 \& Mac } \\
\text { (34:a8:4e:f9:70:80) }\end{array}$ \\
\hline D.3.2 & $\begin{array}{c}-85 \\
\mathrm{dBm}\end{array}$ & Buruk & $\begin{array}{c}\text { Koridor Ruang } \\
\text { C.3.3 \& Mac } \\
\text { (34:a8:4e:f9:70:80) }\end{array}$ \\
\hline
\end{tabular}

\section{Pengaruh Struktur Bangunan Terhadap Kualitas Sinyal}

Jenis material dan bentuk struktur suatu bangunan sangat mempengaruhi dari kualitas sinyal yang dipancarkan pada perangkat access point. Access point yang digunakan pada ssid "imissu@berbudaya" menggunakan type Cisco 3502 Series. Tabel 6 merupakan parameter warna dari kualitas sinyal yang pada software Ekahau Heatmapper. Warna tersebut didapatkan dari hasil mapping denah yang dimasukkan pada software. Untuk warna yang paling bagus berwarna hijau yang mengindikasikan sinyal yang diterima perangkat user sangat bagus. Jika berwarna abu-abu mengindikasikan perangkat tidak mendapatkan jangkauan sinyal yang dikarenakan adanya redaman yang besar dari penghalang (tembok, pintu, jendela).

Tabel 6 Indikator sinyal pada software ekahau.

\begin{tabular}{|l|l|l|l|}
\hline $\begin{array}{l}\text { Warna } \\
\text { coverage }\end{array}$ & $\begin{array}{l}\text { Kuat } \\
\text { sinyal } \\
(\mathrm{dBm})\end{array}$ & $\begin{array}{l}\text { Kualitas } \\
\text { sinyal }\end{array}$ & Keterangan \\
\hline & $-40 \mathrm{~s} / \mathrm{d}-50$ & Baik & $\begin{array}{l}\text { Tanpa } \\
\text { adanya } \\
\text { penghalang }\end{array}$ \\
\hline & $-50 \mathrm{~s} / \mathrm{d}-60$ & Cukup & $\begin{array}{l}\text { Penghalang } \\
\text { tembok tebal }\end{array}$ \\
\hline & Kurang & $\begin{array}{l}\text { Penghalang } \\
\text { tembok } \\
\text { tebal, } \\
\text { kaca, dan } \\
\text { struktur } \\
\text { ruangan }\end{array}$ \\
\hline & $-85 \mathrm{~s} / \mathrm{d}-100$ & Buruk & $\begin{array}{l}\text { Penghalang } \\
\text { tembok } \\
\text { tebal, } \\
\text { kaca, } \\
\text { struktur } \\
\text { ruangan dan } \\
\text { jarak AP } \\
\text { dengan user }\end{array}$ \\
\hline & 100 & $\begin{array}{l}\text { Tidak } \\
\text { mendapatka } \\
\text { n jangkauan } \\
\text { sinyal. }\end{array}$ \\
\hline
\end{tabular}

Gambar 5 merupakan gambaran penempatan AP Cisco pada koridor depan Ruang Sekjur Elektro lantai 1. Dapat dilihat sinyal paling bagus terdapat pada ruangan Sekjur Elektro. Hal ini disebabkan penempatan AP terletak didepan ruang sekjur. Jika dilihat pada ruang Sekjur Mesin dan Sekjur Arsitek untuk kualitas sinyal kurang untuk meliputi satu ruangan sekjur tersebut.

\subsection{Pembahasan}




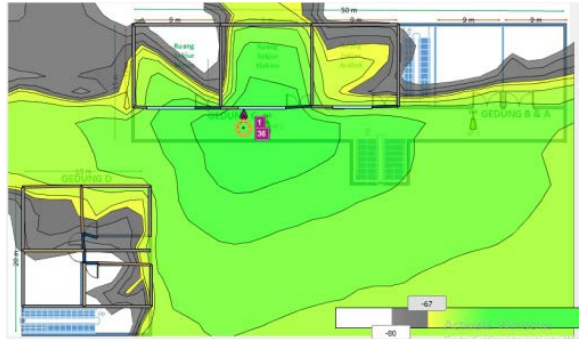

Gambar 5 Visualisasi Sinyal Wi-Fi pada Gedung C dan D lantai 1

Gambar 6 memperlihatkan visualisasi sinyal Wi-Fi pada lantai 2 dapat dilihat untuk penempatan AP yang berada dikoridor gedung C tepatnya didepan antara ruangan C.2.2 \& C.2.3 hanya mampu memenuhi kebutuhan sinyal di area gedung $C$ saja. Untuk kualitas sinyal yang didapatkan pada gedung $D$ kurang bagus.

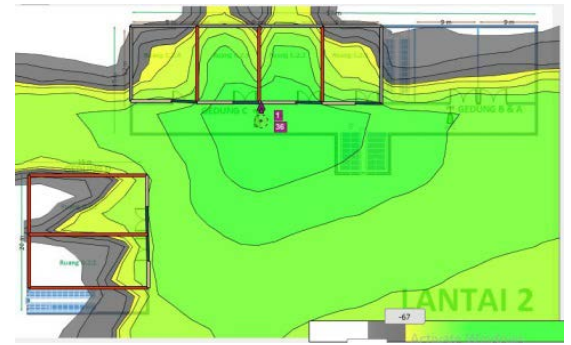

Gambar 6 Visualisasi Sinyal Wi-Fi pada Gedung C dan D lantai 2

Gambaran visualisasi sinyal pada lantai 3 dapat dilihat pada Gambar 7. Untuk kualitas sinyal pada lantai 3 tidak jauh berbeda dengan sinyal yang didapatkan pada gedung $\mathrm{C}$ maupun gedung $D$. jangkauan AP yang diletakkan pada koridor gedung $C$ tidak mampu untuk menanggulangi kebutuhan sinyal yang ada di gedung $D$. Hal ini berkaitan dengan kemampuan pancaran jenis AP yang memiliki pancaran jenis omnidirectional. Selain itu redaman dari penghalang seperti tebal tembok, pintu juga mempengaruhi kualitas sinyal pada gedung $D$.

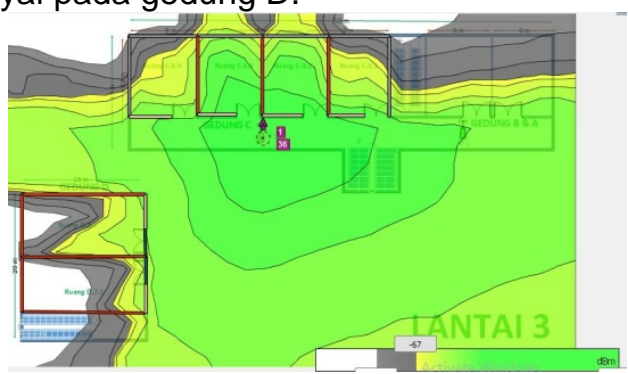

Gambar 7 Visualisasi Sinyal Wi-Fi pada Gedung C dan D lantai 3

Berdasarkan Gambar 8, dapat dilihat bahwa jangkauan sinyal hanya berada disekitaran Ruang Aula gedung C. struktur ruangan pada aula ini hampir secara keseluruhan dikelilingi tembok beton yang memiliki redaman yang besar terhadap pancaran sinyal. Untuk kualitas sinyal pada gedung $C$ dan $D$ lantai 4 dapat dilihat visualisasinya pada gambar 8 dibawah ini.

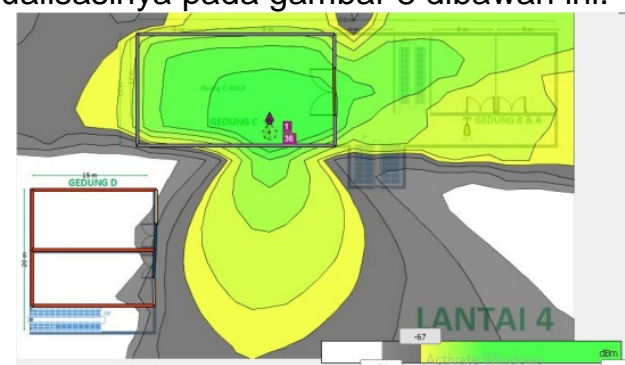

Gambar 8 Visualisasi Sinyal Wi-Fi pada Gedung C dan D lantai 4

\section{Optimasi Jaringan Wifi}

Untuk Optimasi Jaringan Wi-Fipada Gedung Fakultas Teknik Kampus Sudirman Universitas Udayana menggunakan hasil mapping ulang pada ekahau.Optimasi awal yang dirancang ulang pada Gedung C \& D lantai 1 dapat dilihat pada Gambar 9 dibawah ini.

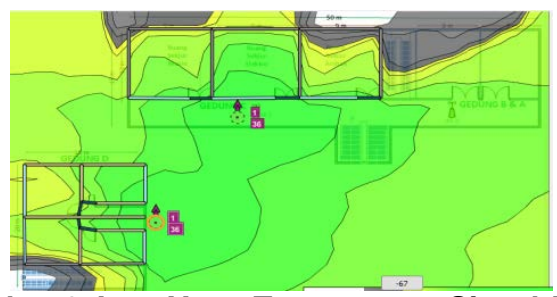

Gambar 9 Area Yang Tercoverage Sinyal Wi-Fi Pada Gedung C dan D Lantai 1

Dalam mengatasi kualitas sinyal pada Gedung D dengan cara menambahkan AP di depan Gedung D antara Ruang D.1.1 dan D.1.2 . Jika ingin memperbaiki kualitas sinyal tanpa adanya penambahan AP akan cukup sulit dikarenakan dari jenis AP Cisco 3500 indoor series ini memiliki pancaran omnidirectional. Dengan pancaran sinyal seperti ini akan sulit menjangkau area gedung D jika penempatan AP hanya di gedung C saja.Untuk hasil optimasi mapping pada lantai 2 dapat dilihat pada Gambar 10 dibawah ini.

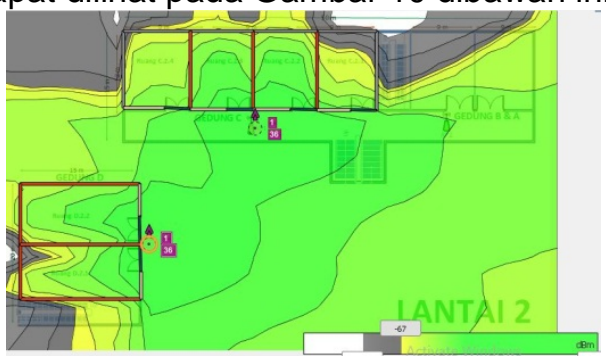

Gambar 10 Area Yang Tercoverage Sinyal Wi-Fi Pada Gedung C dan D Lantai 2 
Gambar 10 diatas, untuk penambahan AP tetap dilakukan di gedung $D$, sama halnya dengan yang dilakukan pada lantai 1. Secara bentuk ruangan lantai 2 dan 3 gedung $D$ sama dan untuk penambahan AP tetap dilakukan di koridor antara dua ruangan tersebut. Untuk optimasi lantai 3 dapat dilihat pada Gambar 11 dibawah ini.

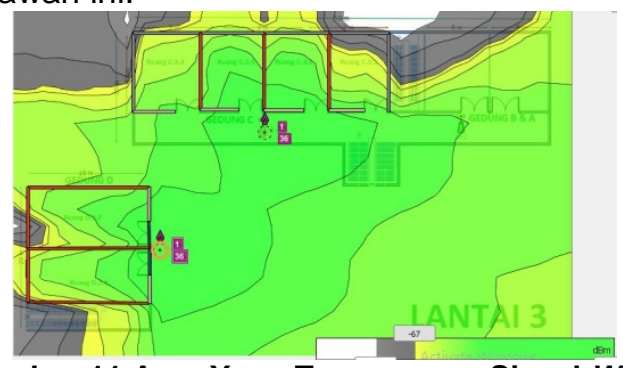

Gambar 11 Area Yang Tercoverage Sinyal Wi-Fi Pada Gedung C dan D Lantai 3

Untuk Gedung D lantai 4 tetap menambahkan 1 AP didepan ruangan Gedung $D$ karena dari hasil pengukuran dan mapping pada ekahau untuk mendapat jangkauan sinyal dari Gedung $C$ ruang aula sudah tidak memungkinkan karena ada redaman yang disebabkan dari kontur tembok. Hasil optimasi pada Gedung D lantai 4 bisa dilihat pada gambar 12 dibawah ini.

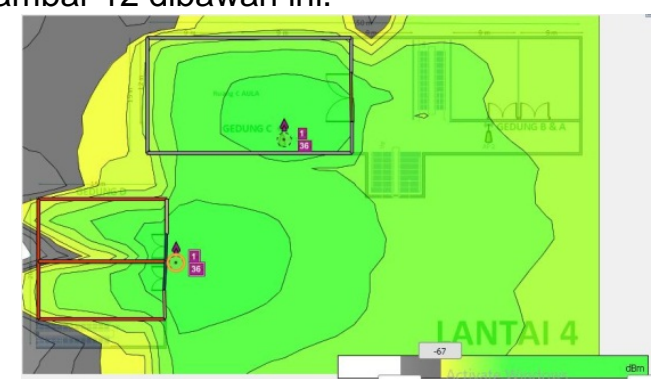

Gambar 12 Area Yang Tercoverage Sinyal Wi-Fi Pada Gedung C dan D Lantai 4

\section{SIMPULAN}

Kami mengukur peningkatan performa Wi$\mathrm{Fi}$ yang ada di Fakultas Teknik Kampus Sudirman Universitas Udayana melalui akses imissu@berbudaya dengan type Cisco 3502 Series. Kualitas sinyal akan cukup sulit ditingkatkan tanpa adanya penambahan AP dikarenakan jenis AP Cisco ini memiliki pancaran omnidirectional. Dengan pancaran sinyal seperti ini akan sulit menjangkau area Gedung $D$ jika penempatan AP hanya di Gedung C saja. Penambahan AP untuk memperbaiki kualitas sinyal dilakukan di Gedung D antara Ruang D.1.1 dan D.1.2 .
[1] Rappaport, Theodora . S.,2002. "Wireless CommunicatioPrinciple", Prentice Hall International Edition, New York.

[2] Kurnia P, Kartika, Budi Santoso T, AdiSiswandari. 2010. Optimasi Sistem WiFi di PENS-ITS.

http://repo.pens.ac.id/282/1/7206040036 m.pdf. diakses pada tahun 2017

[3] Titahningsih, P., Primananda, R., \& Akbar, S. R. (Mei 2017). Perancangan Penempatan Access Point untuk Jaringan Wifi Pada Kereta Api Penumpang. Jurnal Pengembangan Teknologi Informasi dan IImu Komputer, 2008-2015.

[4] Simoneau, P. (2006). The OSI Model: Understanding the Seven Layers of Computer Networks. Global Knowledge Training LLC.

[5] Setya Andini, S., Budi Rahardjo, T., \& Nugraha, E. (n.d.). IEEE $802.11 \mathrm{~g}$.

[6] UniFi Enterprise WiFi System. (2011). United States: Ubiquiti Networks

[7] Soldo K, M. (2013). Wi-Fi Parameter Measurements and Analysis MEASUREMENT 2013, Proceedings of the 9th International Conference, Smolenice, Slovakia , 339-342.

\section{Daftar Pustaka}

